\title{
Prevalence of Ear Disorders at Rabak City, White Nile Province, Sudan, 2017
}

\author{
Mujtaba Alrayah \\ Unit of Otolaryngology, Department of Surgery, Faculty of Medicine, Al-Baha University, Al Bahah, Saudi Arabia \\ Email: Muj536@yahoo.com
}

How to cite this paper: Alrayah, M. (2018) Prevalence of Ear Disorders at Rabak City, White Nile Province, Sudan, 2017. International Journal of Otolaryngology and Head \& Neck Surgery, 7, 375-387.

https://doi.org/10.4236/ijohns.2018.76038

Received: October 21, 2018

Accepted: November 24, 2018

Published: November 27, 2018

Copyright $\odot 2018$ by author and Scientific Research Publishing Inc. This work is licensed under the Creative Commons Attribution International License (CC BY 4.0).

http://creativecommons.org/licenses/by/4.0/

\begin{abstract}
Background: Residence to industrial areas was associated with increased risk of health problems. Lacks of epidemiological data of ear disorders were noticed among Sudanese. Objectives: This study was set out to determine the prevalence of preventable ear disorders in Rabak city, White Nile province in Sudan. Methods: A well-structured open-ended (pro forma) questionnaire was used to screen 300 participants who suffered of ear, nose and throat (ENT) complaints in the industrial area of Rabak city. Ear examinations for participants complaining of ear disorders were conducted using illuminated and pneumatic otoscope, tuning fork and pure tone audiometry. Diagnosis, risk factors and therapeutic outcomes were evaluated. Data were analyzed statistically and manipulated in a suitable manner. Results: Of total $(\mathrm{n}=300)$, only $(\mathrm{n}=186)$ fit the study criteria. About $85(28.6 \%)$ of participants aged 20 - 40 years old, whilst most 99 (33\%) lived at urban-industrial part of the city. The participants who were not working $131(43.6 \%)$ and those with basic level of education were 134 (44.6\%). Otitis externa was prevalent in $50(26.9 \%)$ of our participants. Around $44(23.6 \%)$ were suffering of chronic otitis media and $40(21.4 \%)$ were suffering of otitis media with effusion. Acute otitis media was detected in 27 (14.3\%). Ear wax was detected in 13 (7.1\%), and foreign bodies were found in 12 (6.6\%) of the study population. Smoking was commonest amongst participants with otitis externa. Our results revealed that the preferred treatment modality was medical treatment and follow-up the participants which resulted in good outcome. Conclusion: Preventable ear diseases represent a significant health problem among participants of Rabak city. Amongst the ear problems, the incidence of otitis media and otitis externa due to industrial pollution was reported to be high. Creating comprehensive health education about the common ear disorders in this community can help reduce the prevalence of these conditions and is highly recommended.
\end{abstract}




\section{Keywords}

Ear Disorders, Sudanese, Otitis Media, Otitis Externa, Industrial Area

\section{Introduction}

Ear disorders are serious diseases in underdeveloped country. They are frequently associated with hearing loss, which is the main health issue that affects quality of life. In young children, it retards language development and school progress, both of which have a significant impact in later life. In communities or countries where illiteracy is prevalent, ear and hearing diseases might impair a person's capacity to participate in normal conversation.

Acute otitis externa (AOE) is one of the most common ear disorders; it has been defined as an inflammation of the external auditory canal, most often caused by bacterial infection, it seen frequently among swimmer [1] [2] and common in young adult population particularly in females [3] [4]. It may be accompanied by various pathological manifestations such as pain, external ear tenderness, redness, swelling of the external ear canal, and occasionally purulent exudate [5]. Management of AOE include; analgesic treatment, topical preparations and systemic antimicrobial, if, there is extension outside of the ear canal [6]

Malignant otitis externa is another type of otitis externa, it's an invasive, potentially life-threatening infection of the external ear and skull base that requires urgent diagnosis and treatment [7]. Patients usually presented with severe persistent otalgia, purulent otorrhea, granulation tissue in the external auditory canal [8]. Treatment includes: local debridement, parenteral antibiotics, surgery on severe cases and follow up [9].

Moreover, Otitis media with effusion (OME) is a very common entity in the pediatric population in devolving countries [10]; it's one of the commonest causes of childhood hearing loss [11]. It is treated medically orsurgically in the form of grommet insertion, with or without adenoidectomy [12] [13]. Follow up is crucial, sochildren with persistent OME should be re-examined at 3- to 6-month intervals until the effusion is no longer present [14].

Another serious ear disorder is Acute otitis media, it's defined as an inflammation of middle ear cleft, which is common at day care children and at low socioeconomic class populations [15] [16]. It has been found that, one in every 4 children will have at least 1 episode of acute otitis media (AOM) by age 10 years [17]. It proceeded by a respiratory infection and characterized with fever, ear pain, hearing loss, bulging red ear drum. Sometimes maybe complicated with ear discharge following ear perforation [18] [19]. Acute and chronic otitis media may manifest as tinnitus and vertigo [20] [21]. In order to relieve pain, hearing loss, acute otitis media, the treatment necessitates analgesic, nasal drops and oral antibiotic [22] [23]. The surgical treatment includes; Myringotomy which can be 
reserved for complications such as mastoiditis, or ear discharge continues beyond 14 days [24]. Unhealed large ear perforation requires ear drum grafting using facia, cartilage or perichondrium [25].

Chronic suppurative otitis media is the main cause of hearing loss in developing countries and it is a major burden on the already limited resources of such countries. It manifested as purulent, odorless or offensive ear drainage [26], occasionally headache, fever and altered mental status present if intracranial infection occur [27].

Wax impaction is a known relatively common cause of hearing loss in under developed country, usually of the mild conductive type [28]. Treatment of ear wax includes sodium bicarbonate ear drops or hydrogen peroxide in glycerol followed by mechanical syringing [29] [30].

At last Foreign bodies in the ear, nose and throat are occasionally seen in family medicine, usually in children, commonly beads and others inorganic objects [31]. It's best treated with removal under general anesthesia with specialist of Otolaryngology [32].

Residence in industrial city like Rabak, which hosted many big factories like sugar and cement, with obvious pollutions, is associated with increased risk of health problems. Ear disorders are common clinical problem in general practice, yet there are remarkably few data available about the demographic characteristics of patients with these conditions and the management approaches used by general practitioners (GPs) in Sudan.

The study was designed to determine the prevalence of ear diseases, their risk factors, common presentation and to identify the types of management and their outcomes among the participants presented at Rabak hospital, White Nile province at Sudan during 2017.

\section{Methodology}

\subsection{Ethical Considerations}

The study was approved by the Health Insurance Research Committee, White Nile state, in the form of Ethical Clearance. Besides, patient verbal informed consent was obtained by all participantsor their co-patients in individualized patterns.

\subsection{Study Design}

A prospective cross-sectional, hospital-based study was conducted during the period between August to November 2017 among patients presenting to the Health Insurance ENT clinics at Rabak city, Sudan.

\subsection{Study Population}

All patients attending Rabak city ENT clinics suffering of any ear problems during the study period who fit the study inclusion criteria were enrolled voluntarily. 


\subsubsection{Inclusion Criteria}

The study inclusion criteria include; both sex, males and females who are resident in the industrial area of Rabak city and suffering of ear disorders. The total number of the eligible participants was 186 out of 300 individuals.

\subsubsection{Exclusion Criteria}

The study exclusion criteria include; any individual with incomplete investigations or had ENT complaint other than ear compliant. About $(n=114)$ were excluded.

\subsection{Sample Size Estimation}

The simplest formula of sample size determination $(\mathrm{N}=\mathrm{PQZ2} / \mathrm{d} 2)$ was used to estimate our sample size $(\mathrm{N}=300)$.

Where $\mathrm{N}=$ sample size, $\mathrm{P}=$ prevalence of ear disorders factor, $\mathrm{Q}=1-\mathrm{p}, \mathrm{Z}=$ constant $95 \%$ occurred 1.96 , and $\mathrm{d}=$ desired margin.

\subsection{Data Collection Procedure}

Data were collected using well-designed questionnaire. The participants of the study were approached by asking questions regarding their personal data, ear-related symptoms, whilst investigator performed clinical examinations, earrelated diagnosis, investigations and the management. In addition to checking the records of the treated patients and their referral, especially for those in need of special surgical interventions. All patients had undergone a detailed history and a complete physical examination by the ENT consultant. Appropriate investigations were requested depending upon the patient's complaint.

\subsection{Data Analysis}

The patients' data were analyzed statistically using the SPSS version 21 . The descriptive statistical summarization was done. The associations between patients' personal data and risk factors with the dependent variables were conducted using chi-square test. Result considered significant at p-value less than 0.05 .

\section{Results}

Table 1 shows that the majority $85(28.6 \%)$ of participants aged 20 - 40 years old, of both sex. The most population 99 (33\%) live at the urban industrial part of the city. Those who are not working comprise 131 (43.6\%) and those with basic level of education are134 (44.6).

Our results revealed that there are five main common of ear disorders which occur separately or in combination. Most of ear problems were ear pain (34.2\%) see Figure 1.

In our study ear pain was common in the age group (10 - 20), with male predominance, among non-worker populations, in those who live in Urban and urban industrial and those with basic level of education, see Table 2. 
Clinical examinations showed that external ear tenderness signs were the common for patients suffering of ear problems (Figure 2).

Otitis externa was noticed as the commonest diagnosis among participant with ear disorders. See Figure 3.

Medical treatments were the commonest modalities of treatments among patients with otitis externa and otitis media, see Figure 4.

The most common treatment outcome among participants was treatment and follow-up (38\%), see Figure 5.

Smoking was commonest amongst participants with otitis externa, as shown in Figure 6.

Table 1. Demographic data, $\mathrm{n}=300$.

\begin{tabular}{|c|c|c|}
\hline Patterns & Frequency/Percentage & p-value \\
\hline \multicolumn{3}{|l|}{ 1- Age } \\
\hline$<5$ & $27(9)$ & $<0.000$ \\
\hline $5<10$ & $39(13)$ & \\
\hline $10<20$ & $63(21)$ & \\
\hline $20<40$ & $86(28.6)$ & \\
\hline $40<60$ & $69(23)$ & \\
\hline $60>$ & $16(5)$ & \\
\hline \multicolumn{3}{|l|}{ 2- $\quad$ Sex } \\
\hline Male & $160(53.3)$ & 0.270 \\
\hline Female & $140(46.6)$ & \\
\hline \multicolumn{3}{|l|}{ 3- Residence } \\
\hline Urban & $89(29.6)$ & $<0.000$ \\
\hline Urban-industrial & $99(33)$ & \\
\hline Rural & $43(14.3)$ & \\
\hline Rural industrial & $56(18.6)$ & \\
\hline Others & $13(4.3)$ & \\
\hline \multicolumn{3}{|l|}{ 4- Occupation } \\
\hline Industrial worker & $30(10)$ & $<0.000$ \\
\hline Farmer & $36(12)$ & \\
\hline Officer & $22(7.3)$ & \\
\hline Free duties & $41(13.6)$ & \\
\hline Security officer & $6(2)$ & \\
\hline Other occupations & $7(2.3)$ & \\
\hline Not working & $131(43.6)$ & \\
\hline Child & $27(9)$ & \\
\hline \multicolumn{3}{|l|}{ 5- Education } \\
\hline Illiterate & $28(9.3)$ & $<0.000$ \\
\hline Basic & $134(44.6)$ & \\
\hline Secondary & $54(18)$ & \\
\hline University and more & $57(19)$ & \\
\hline Preschool & $27(9)$ & \\
\hline
\end{tabular}

NB: Free duties is any participant without job such as hawkers and porters. 
Table 2. The relationship between Demographic and ear problems, $\mathrm{n}=80$.

\begin{tabular}{|c|c|c|c|c|c|c|}
\hline \multirow{2}{*}{\multicolumn{2}{|c|}{$\begin{array}{l}\text { Patterns Ear pain } \\
\text { Frequency/Percentage }\end{array}$}} & \multirow[t]{2}{*}{ Ear discharge } & \multicolumn{2}{|c|}{ Hearing loss } & Tinnitus & Vertigo \\
\hline & & & & & & \\
\hline \multirow[t]{7}{*}{$1-$} & Age & $n=63$ & $\mathrm{n}=4$ & $\mathrm{n}=5$ & $\mathrm{n}=3$ & $\mathrm{n}=5$ \\
\hline & $<5$ & $8(13)$ & $0(0)$ & $0(0)$ & $0(0)$ & $0(0)$ \\
\hline & $5<10$ & $7(11)$ & $1(25)$ & $1(20)$ & $1(33)$ & $0(0)$ \\
\hline & $10<20$ & $16(25)$ & $0(0)$ & $0(0)$ & $0(0)$ & $0(0)$ \\
\hline & $20<40$ & $13(21)$ & $2(50)$ & $0(0)$ & $1(33)$ & $4(75)$ \\
\hline & $40<60$ & $15(24)$ & $1(25)$ & $4(80)$ & $1(34)$ & $1(25)$ \\
\hline & $60>$ & $4(6)$ & $0(0)$ & $0(0)$ & $0(0)$ & $0(0)$ \\
\hline \multicolumn{2}{|c|}{ p-value } & & & & 0.135 & \\
\hline \multirow[t]{3}{*}{$2-$} & Sex & $\mathrm{n}=63$ & $\mathrm{n}=4$ & $\mathrm{n}=5$ & $\mathrm{n}=3$ & $\mathrm{n}=5$ \\
\hline & Male & $40(63)$ & $2(50)$ & $4(80)$ & $1(33)$ & $3(60)$ \\
\hline & Female & $23(37)$ & $2(50)$ & $1(20)$ & $2(67)$ & $2(40)$ \\
\hline \multicolumn{2}{|c|}{ p-value } & & & & 0.654 & \\
\hline \multirow[t]{6}{*}{$3-$} & Residence & $\mathrm{n}=63$ & $\mathrm{n}=4$ & $\mathrm{n}=5$ & $\mathrm{n}=3$ & $\mathrm{n}=5$ \\
\hline & Urban & 19() & $0(0)$ & $1(20)$ & $1(33)$ & $2(40)$ \\
\hline & Urban ind & 21() & $0(0)$ & $4(80)$ & $0(0)$ & $2(40)$ \\
\hline & Rural & 7() & $1(25)$ & $0(0)$ & $2(67)$ & $1(20)$ \\
\hline & Rural-ind & 12() & $1(25)$ & $0(0)$ & $0(0)$ & $0(0)$ \\
\hline & Others & 4() & $2(50)$ & $0(0)$ & $0(0)$ & $0(0)$ \\
\hline \multicolumn{2}{|c|}{ p-value } & & & & 0.003 & \\
\hline \multirow[t]{9}{*}{ 4- } & Occupation & $\mathrm{n}=63$ & $\mathrm{n}=4$ & $\mathrm{n}=5$ & $\mathrm{n}=3$ & $\mathrm{n}=5$ \\
\hline & Indust-worker & $7(11)$ & $0(0)$ & $2(40)$ & $0(0)$ & $0(0)$ \\
\hline & Farmer & $10(16)$ & $1(25)$ & $1(20)$ & $1(33)$ & $0(0)$ \\
\hline & Officer & $7(11)$ & $0(0)$ & $0(0)$ & $0(0)$ & $0(0)$ \\
\hline & Free duties & $7(11)$ & $0(0)$ & $1(20)$ & $1(33)$ & $2(40)$ \\
\hline & Security office & $5(8)$ & $0(0)$ & $0(0)$ & $0(0)$ & $0(0)$ \\
\hline & Others & $3(5)$ & $0(0)$ & $0(0)$ & $0(0)$ & $1(20)$ \\
\hline & Not working & $16(25)$ & $3(75)$ & $1(20)$ & $1(34)$ & $2(40)$ \\
\hline & Child & $8(13)$ & $0(0)$ & $0(0)$ & $0(0)$ & $0(0)$ \\
\hline \multicolumn{2}{|c|}{ p-value } & & & & 0.283 & \\
\hline
\end{tabular}

NB: any combination of two or more clinical conditions $(n=106)$ were excluded from the table, to avoid complications and duplications.

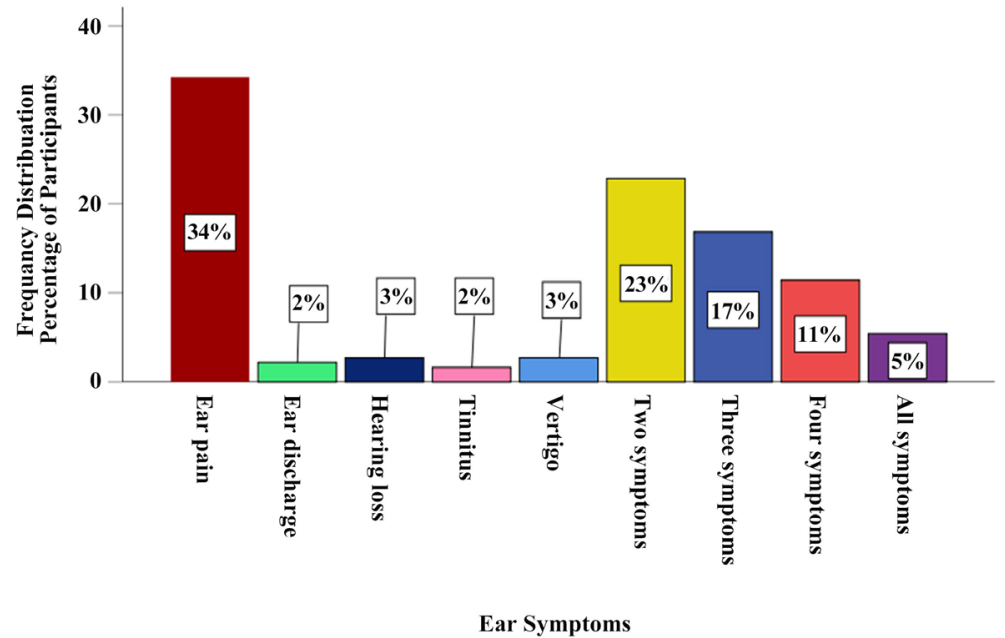

Figure 1. The frequency distribution percentage of the five main otological symptoms reported among the study populations. 


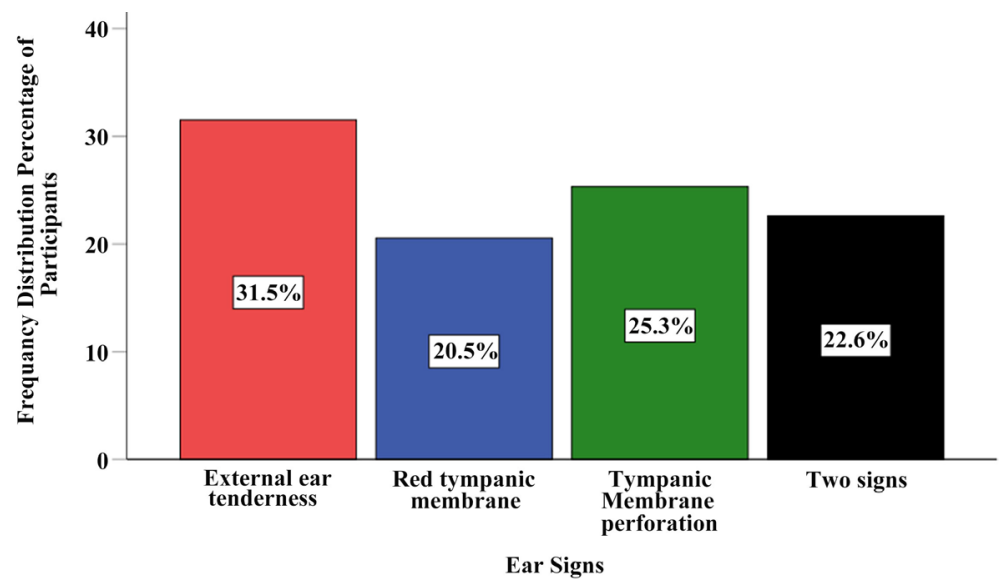

Figure 2. The frequency distribution percentage of ear signs among the participants with ear disorders.
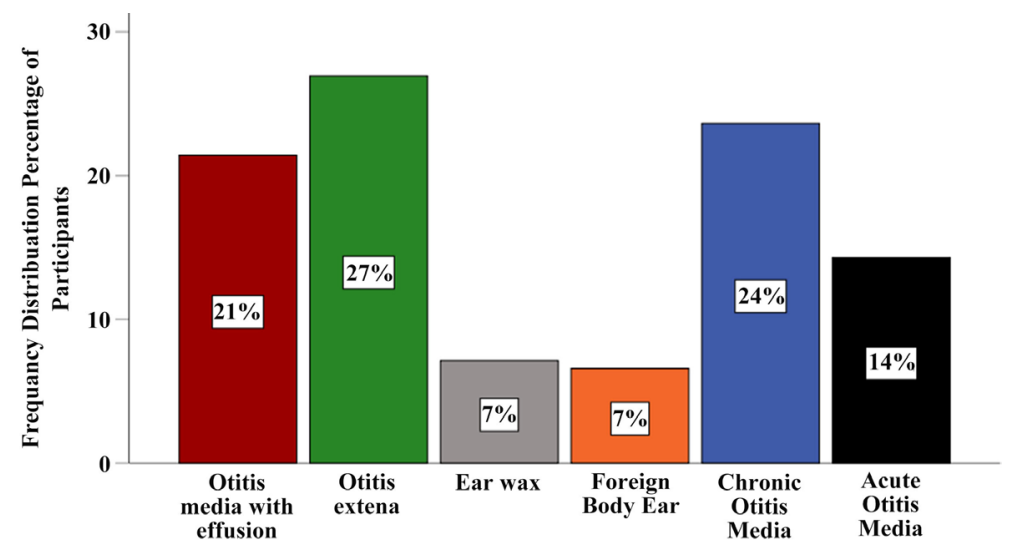

Ear Disorders

Figure 3. The frequency distribution percentageof ear disorders diagnosis among participants.

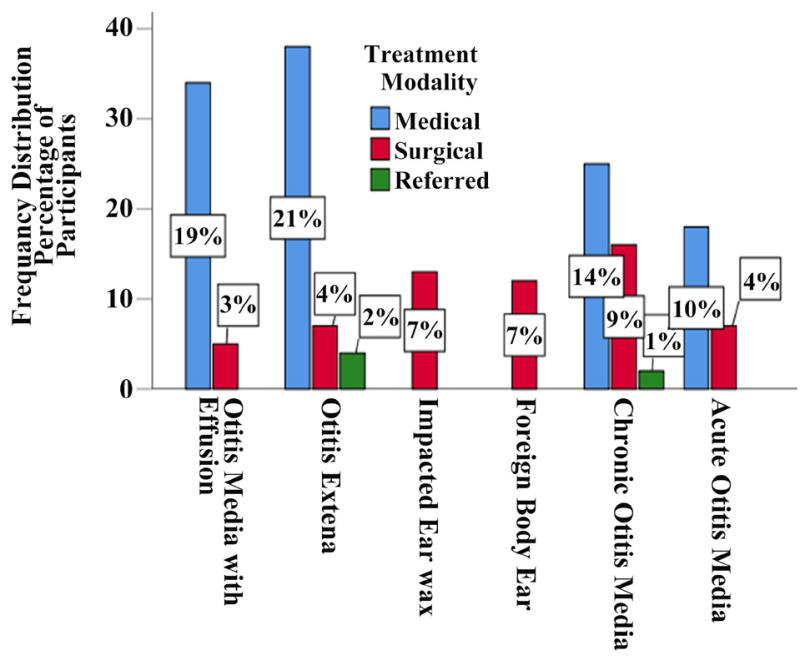

Ear Disorders

Figure 4. The frequency distribution of treatment modalities among participants with ear disorders. 


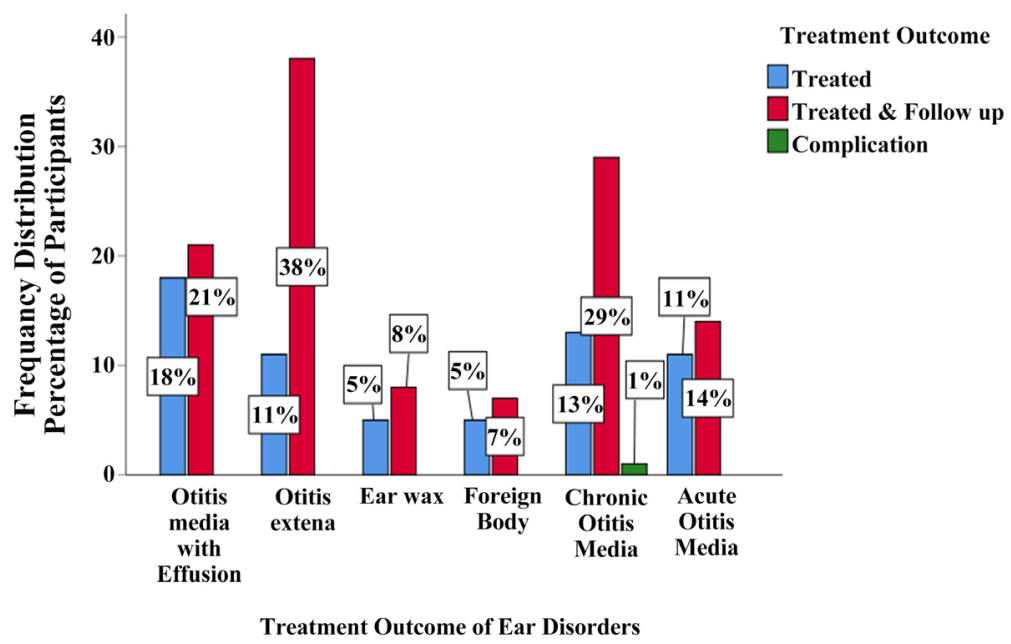

Figure 5. The frequency distribution of treatment outcome among participants with ear disorders.

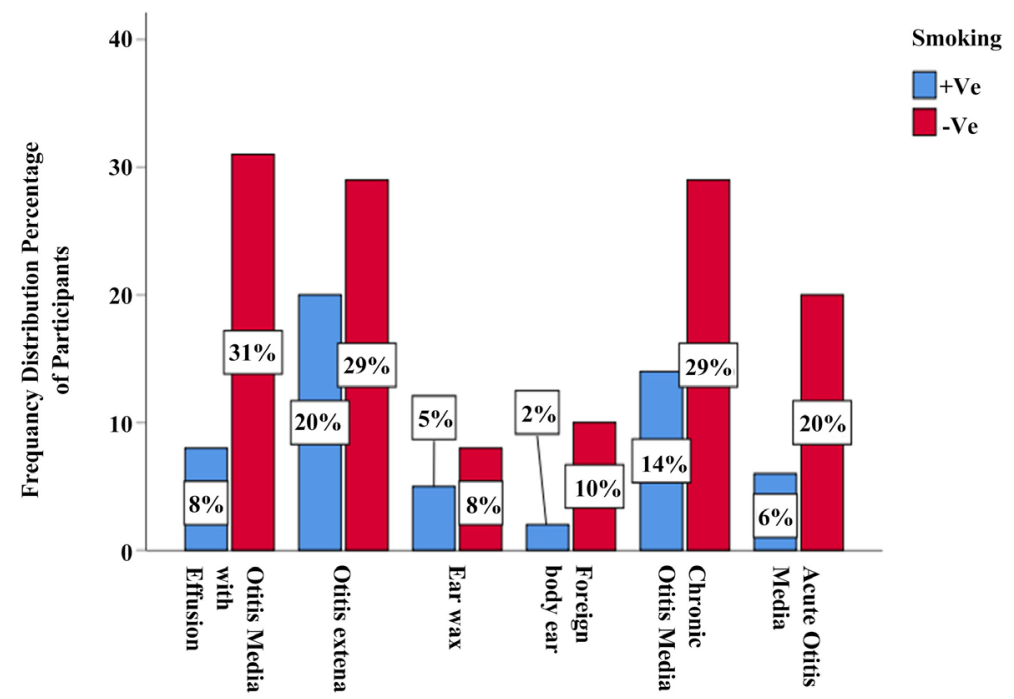

Figure 6. The frequency distribution percentage of smoking among participants with ear disorders. NB: Smoking +ve is the participant who smoke, whilst Smoking -ve is the participant who don't smoke.

\section{Discussion}

Industrial areas were associated with increased risk of health problems particularly ear disorders where few data available in Sudan.

Our results revealed that, majority of participant were young adult of both sex, this because pediatric population with ENT disorders used to be treated in pediatric clinics which considered as miss-concept that pediatric ENT patient should be managed by pediatrician. The incidence among elderly was generally not common, this was agreed with Ronal et al., [3] who stated that, elder population were have less common ear disorders.

Majority of population in this study lived at urban-industrial part of the city, where a high rate of pollution was reported and thought to be associated with 
ear problems, moreover good health facilities were available in contrast to rural area, this disagreed with Minja and Machemba [33] who stated that, rural population were having more hospital visits because of more ear complications.

Most of participants were not working and with basic level of education, this is because White Nile province hosting hundreds of refugees from different parts of the country and neighbor countries and this province is not prepared well to welcome those refugees., this agreed with Czechowicz et al., [15] who stated that, hearing problems due to different ear disorders were common among low socioeconomic population.

The most common ear symptoms reported among the study participants was severe ear pain (measured with a scale system of severity from 1 to 10), this is because the otitis externa was the commonest diagnosis. This is in agreement with morbidity and mortality weekly report [5], Pukander [17] and agreed with Heikkinen, and Ruuskanen [18]. External ear tenderness, edema of the externalauditory canal with purulent or fungal masses were reported on reaching this diagnosis.

The relationship between demographic factors and the main ear symptoms, ear pain revealed that it was common in the age group (10 - 20), with male predominance, among non-worker populations who lived in Urban and urban industrial and those with basic level of education. This can be taken as an evidence that, the majority of those participants were diagnosed with otitis media with effusion. Acute otitis media and otitis externa as a complication of the last conditions, which are known diseases of childhood, common in male because they usually in outdoor. This agreed with Robb, and Williamson [11]

Clinical examinations showed that external ear tenderness was the commonest sign, during manipulation of the auricle. This is due to the special clinical signs of otitis externa. This agreed with morbidity and mortality weekly report [5]. Also, high numbers of participants were having tympanic membrane perforation, this is a known complication that might occur following untreated acute or chronic otitis media. Again this agreed with Pukander [17] and agreed with Heikkinenand Ruuskanen [18].

On other hand, otitis externa was noticed as the commonest diagnosis among participants with ear disorders, this because Rabak city located at near white Nile, and most of the participants used to swim regularly on this contaminated water at the river's canals of the surrounding factories leading them to external canal humidity and bacterial contamination. This why they developed otitis externa, and this agreed with Sander [1], also agreed with Hajioff and his team workers [2] and agreed with Rowlands and his colleagues who mentioned that, the diagnosis of otitis externa was common among young adult population [3]. Moreover, this agreed with Calderon and his team workers [4] who described otitis externa to occur commonly at young adult population with poor ear hygiene.

Furthermore, concerning ear problems diagnosis, high numbers of participants were diagnosed with chronic suppurative otitis media including both safe 
and un-safe type. This because chronic otitis media is a known ear disorders at developing countries with poor health care facilities. This agreed with Czechowicz, et al., [15].

Besides, participants diagnosed with otitis media with effusion and otitis media were not few in numbers, most of them were children, since children have short wide Eustachian tubes and presented with ear pain and hearing loss. This in line with Williamson [10] and Robb, and Williamson [11].

In Contrary, few numbers of participants were diagnosed with impacted ear wax, because most of the population used to treat themselves alone by putting sodium bicarbonate ear drops as an over the counter drug (OTC). This result was is contradicting with Burton, and Doree [28] who stated that, impacted ear wax is one of the most common ear disorders that people visit their general practitioners.

Moreover, few numbers of participants were diagnosed with ear's foreign body, this is because it is an urgent condition which needs immediate intervention at well-equipped hospital and not are expected to visit us at the insurance clinics where only cold cases are treated. This agreed with Di Muzioand Deschler [31], who stated that, pediatric patients can be successfully managed by skilled emergency department personnel with low complication rates.

Majority of participants who suffered from otitis externa were treated medically with analgesic, topical preparations and systemic antimicrobials. This agreed with Rosenfeld [6] and his team, stating that, otitis externa should be treated with topical antibiotic and systemic antibiotics if the infection spread beyond the external auditory canal. On the other hand, patients with malignant otitis externa were treated surgically and using parenteral antibiotics. This in line with Stevens and his team [9].

Participants diagnosed with otitis media with effusion were treated medically with nasal drops and oral antibiotics, some participants required grommet tube insertion with adenotonsillectomy to enhance drainage of middle ear effusion. This agreed with Robband Williamson [11], Atkinson Wallis and Coates worth [12].

Participants whom diagnosed as chronic otitis media required medical treatment only, because they did not present with any extracranial or intracranial complications, whilst participants with mastoiditis required mastoidectomy. This was agreed with Das, et al., [25].

Patients with acute otitis media were treated medically with analgesics, nasal drops and oral antibiotics, because they presented without ear complications, as mentioned by Del Mar, et al., [21] and van Buchem and his team [21], in addition, myringotomy spared for participants with otitis media who did not benefit from local and systemic medical treatment. This agreed with Van Buchem, et al., [22].

Patients with ear wax were prescribed sodium bicarbonate in order to liquify the impacted wax then followed 3 days later with ear syringing. This agreed with Burtonand Doree [28] and Loveman, et al., [30]. 
Regarding children diagnosed with foreign body ear, they were managed with foreign body removal under general anesthesia, which considered as the best way to remove foreign body from child ear, because of their excessive movement, furthermore, it carries the lowest risk for iatrogenic ear traumas, this agreed with Daviesand Benger [32].

The most common management plan among the study participants was the treatment and follow-up, which was crucial on participants with malignant otitis externa since they might developed cranial complications, this agreed with Carfrae and Kesser [7]. Moreover, patients with otitis media with effusion needed regular follow-up using otoscopic examination to detect any residual tympanic fluid, this agreed with Qureishi, et al., [14].

Smoking as a risk factor was found to be more associated with otitis externa. In the literature smoking particularly, the passive type is known to be a risk factor for Otitis media in childhood. In our series smoking was associated with Otitis externa because there was a little relative number of children participating on this study, which was contradicting with Uhari [27] who stated that, parenteral smoking is a known risk factor for acute otitis media.

\section{Conclusions}

Finally, we concluded that, ear disorders were common ENT disorders, especially otitis externa and otitis media in this polluted area, affecting mainly young adult population. On the other hand, otitis media with effusion was more prevalent on childhood, most of these disorders were found mainly among population living within the industrial areas of Rabak city. Moreover, these disorders were common among lower education strata of the population and among participants with basic education and in non-working population.

Our findings stated that, patients suffering ear pain should be examined carefully for evidence of both external or middle ear infections and young adult should be focused on prohibiting those bad ear habits such as ear manipulations using different tools. Swimmers should be advised to put in earplugs and avoid swimming in lakes, ponds, or rivers with lots of bacteria; in addition, ear wax is necessary for good ear health. In fact, it actively fights infections. Therefore, cleaning them frequently could put individual at risk of further problems.

Creating comprehensive health education and health promotion program about the common Ear disorders in this community can help reduce the prevalence of these conditions. Moreover, strengthening the primary health care services and invest more in training of the health personals to deal properly with common Ear disorders can reduce the burden of these diseases in the community. More efforts are needed to settle the occupational health services in this industrial community concerning the worker health services, environmental services and protection of the population from the resulting hazards. In addition, promotion of the hazardless farming and industrial activities in this area can alleviate the burden of these disorders among this limited recourse community. 


\section{Conflicts of Interest}

The author declares no conflicts of interest regarding the publication of this paper.

\section{References}

[1] Sander, R. (2001) Otitis Externa: A Practical Guide to Treatment and Prevention. American Family Physician, 63, 927-936, 941-942.

[2] Hajioff, D. and MacKeith, S. (2015) Otitis Externa. BMJ Clinical Evidence, 2015, 0510 .

[3] Rowlands, S., et al. (2001) Otitis Externa in UK General Practice: A Survey Using the UK General Practice Research Database. British Journal of General Practice, 51, 533-538.

[4] Calderon, R. and Mood, E.W. (1982) An Epidemiological Assessment of Water Quality and "Swimmer's Ear". Archives of Environmental Health: An International Journal, 37, 300-305. https://doi.org/10.1080/00039896.1982.10667583

[5] (2011) Estimated Burden of Acute Otitis Externa-United States, 2003-2007. MMWR Morbidity and Mortality Weekly Report, 60, 605-609.

[6] Rosenfeld, R.M., et al. (2006) Clinical Practice Guideline: Acute Otitis Externa. Otolaryngology-Head and Neck Surgery, 134, S4-S23. https://doi.org/10.1016/j.otohns.2006.02.014

[7] Carfrae, M.J. and Kesser, B.W. (2008) Malignant Otitis Externa. Otolaryngologic Clinics of North America, 41,537-549. https://doi.org/10.1016/j.otc.2008.01.004

[8] Karaman, E., et al. (2012) Malignant Otitis Externa. Journal of Craniofacial Surgery, 23, 1748-1751. https://doi.org/10.1097/SCS.0b013e31825e4d9a

[9] Stevens, S.M., et al. (2015) Malignant Otitis Externa: A Novel Stratification Protocol for Predicting Treatment Outcomes. Otology \& Neurotology, 36, 1492-1498. https://doi.org/10.1097/MAO.0000000000000839

[10] Williamson, I. (2015) Otitis Media with Effusion in Children. BMJ Clinical Evidence, 2015, 0502.

[11] Robb, P.J. and Williamson, I. (2016) Otitis Media with Effusion in Children: Current Management. Paediatrics and Child Health, 26, 9-14. https://doi.org/10.1016/j.paed.2015.09.002

[12] Atkinson, H., Wallis, S. and Coatesworth, A.P. (2015) Otitis Media with Effusion. Postgraduate Medicine, 127, 381-385. https://doi.org/10.1080/00325481.2015.1028317

[13] Prabakaran, J. and Radhakrishnan, S. (2016) Prevalence and Management of Otitis Media with Effusion amongst the School Going Children of a Rural Area in Puducherry. 24,8 .

[14] Qureishi, A., et al. (2014) Update on Otitis Media-Prevention and Treatment. Infection and Drug Resistance, 7, 15-24.

[15] Czechowicz, J.A., et al. (2010) Hearing Impairment and Poverty: The Epidemiology of Ear Disease in Peruvian Schoolchildren. Otolaryngology-Head and Neck Surgery, 142, 272-277. https://doi.org/10.1016/j.otohns.2009.10.040

[16] Uhari, M., Mäntysaari, K. and Niemelä, M. (1996) Meta-Analytic Review of the Risk Factors for Acute Otitis Media. Clinical Infectious Diseases, 22, 1079-1083. https://doi.org/10.1093/clinids/22.6.1079

[17] Dickson, G. (2014) Acute Otitis Media. Primary Care: Clinics in Office Practice, 41, 
11-18. https://doi.org/10.1016/j.pop.2013.10.002

[18] Pukander, J. (1983) Clinical Features of Acute Otitis Media among Children. Acta Oto-Laryngologica, 95, 117-122. https://doi.org/10.3109/00016488309130924

[19] Heikkinen, T. and Ruuskanen, O. (1995) Signs and Symptoms Predicting Acute Otitis Media. Archives of Pediatrics \& Adolescent Medicine, 149, 26-29. https://doi.org/10.1001/archpedi.1995.02170130028006

[20] Riina, N., Ilmari, P. and Kentala, E. (2005) Vertigo and Imbalance in Children: A Retrospective Study in a Helsinki University Otorhinolaryngology Clinic. Archives of Otolaryngology-Head \& Neck Surgery, 131, 996-1000. https://doi.org/10.1001/archotol.131.11.996

[21] Kim, D.-K., et al. (2011) Tinnitus in Patients with Chronic Otitis Media Before and after Middle Ear Surgery. European Archives of Oto-Rhino-Laryngology, 268, 1443-1448. https://doi.org/10.1007/s00405-011-1519-9

[22] Del Mar, C.B., Paul, P.G. and Hayem, M. (1997) Are Antibiotics Indicated as Initial Treatment for Children with Acute Otitis Media? A Meta-Analysis. BMJ, 314, 1526. https://doi.org/10.1136/bmj.314.7093.1526

[23] van Buchem, F.L., Peeters, M.F. and van't Hof, M.A. (1985) Acute Otitis Media: A New Treatment Strategy. British Medical Journal, 290, 1033-1037. https://doi.org/10.1136/bmj.290.6474.1033

[24] Van Buchem, F.L., Dunk, J.H.M. and van't Hof, M.A. (1981) Therapy of Acute Otitis Media: Myringotomy, Antibiotics, or Neither? A Double-Blind Study in Children. The Lancet, 318, 883-887. https://doi.org/10.1016/S0140-6736(81)91388-X

[25] Dornhoffer, J.L. (1997) Hearing Results with Cartilage Tympanoplasty. The Laryngoscope, 107, 1094-1099. https://doi.org/10.1097/00005537-199708000-00016

[26] Das, C.P., et al. (2017) A Study of the Clinical Correlation of Clinical Features, Radiological and Operative Findings in Chronic Suppurative Otitis Media with Cholesteatoma. Indian Journal of Applied Research, 7, Article No. 33.

[27] Schwaber, M.K., Pensak, M.L. and Bartels, L.J. (1989) The Early Signs and Symptoms of Neurotologic Complications of Chronic Suppurative Otitis Media. The Laryngoscope, 99, 373-375. https://doi.org/10.1288/00005537-198904000-00002

[28] Burton, M.J. and Doree, C.J. (2003) Ear Drops for the Removal of Ear Wax. Cochrane Database of Systematic Reviews, No. 3, CD004400.

[29] Burton, M.J. and Doree, C.J. (2009) Ear Drops for the Removal of Ear Wax. Cochrane Database of Systematic Reviews, No. 1, CD004326.

[30] Loveman, E., et al. (2011) Ear Wax Removal Interventions: A Systematic Review and Economic Evaluation. British Journal of General Practice, 61, e680-e683. https://doi.org/10.3399/bjgp11X601497

[31] DiMuzio, J.J. and D.G. Deschler (2002) Emergency Department Management of Foreign Bodies of the External Ear Canal in Children. Otology \& Neurotology, 23, 473-475. https://doi.org/10.1097/00129492-200207000-00014

[32] Davies, P.H. and Benger, J.R. (2000) Foreign Bodies in the Nose and Ear: A Review of Techniques for Removal in the Emergency Department. Journal of Accident \&amp; Emergency Medicine, 17, 91-94. https://doi.org/10.1136/emj.17.2.91

[33] Minja, B.M. and Machemba, A. (1996) Prevalence of Otitis Media, Hearing Impairment and Cerumen Impaction among School Children in Rural and Urban Dar es Salaam, Tanzania. International Journal of Pediatric Otorhinolaryngology, 37, 29-34. https://doi.org/10.1016/0165-5876(96)01363-8 